\title{
Key Emerging Issues in Higher Education, Fiji
}

\author{
Prashneel Ravisan Goundar ${ }^{1}$ \\ ${ }^{1}$ Department of Language \& Literature, Fiji National University, Lautoka, Fiji \\ Correspondence: Prashneel Ravisan Goundar. E-mail: prgoundar@gmail.com or prashneel.goundar@fnu.ac.fj
}

Received: April 23, 2019

doi:10.5539/ass.v15n6p96
Accepted: May 1, $2019 \quad$ Online Published: May 31, 2019

URL: https://doi.org/10.5539/ass.v15n6p96

\begin{abstract}
Fiji, an island nation located in the South Pacific has three major higher education institutions namely, "The Fiji National University, The University of the South Pacific which is also 'the oldest university' in the country and The University of Fiji". This paper reviews key emerging issues that are being encountered in higher education (HE) in Fiji. The key issues' faced by these universities, is showing a similar trend in higher education internationally which this paper examines. Plagiarism continues to be a global phenomenon which the literature objectively highlights along with problems arising due to heavy workload and negligence of not incorporating inclusive education. The paper explores possible solutions to these issues drawing evidence from the available literature. Further research on individual universities would provide greater data for analysis as well as broader solutions to the issues.
\end{abstract}

Keywords: higher education, Fiji, plagiarism, workload, enrolment, inclusive education

\section{Introduction}

The Republic of Fiji is "an upper middle-income country in the South Pacific" (Healey, 2018). The "population is approximately 920,000, of whom 56.8\% are iTaukei (indigenous Melanesians) and 37.5\% are Indo-Fijian descendants of indentured labourers ('Girmitiyas') from India who arrived in Fiji in the late $19^{\text {th }}$ and early $20^{\text {th }}$ century" (Central Intelligence Agency, 2017). Fiji's location makes it 'the hub of the region', with a pivotal 'economic and political role' in the South Pacific. It is "an independent country located in the middle of the Southwestern Pacific, about 2,500km northeast of the nearest point in Australia, on the Queensland coast (about $3,100 \mathrm{~km}$ from Sydney and 2,000km north of New Zealand" (Mangubhai \& Mugler, 2003). Fiji is a pluralistic society with one of the reasons being the indenture system (1879-1916). The country has "three main Higher Education Institutions, Fiji National University, The University of Fiji, and The University of the South Pacific" which have intakes from almost 14 Pacific Island Nations as well Asia and Europe which adds to the diversity of learners' background in the classrooms.

First of the three main tertiary institutes in Fiji is "The University of the South Pacific" (USP). It is the oldest higher education provider in Fiji that was established in 1968. USP distinguishes itself to be "the premier institution of higher learning for the Pacific region, uniquely placed in a region of extraordinary physical, social and economic diversity" (USP.ac.fj, 2013). In addition, "USP has set a high standard for quality in its research. Major research commitments include business management, teacher education, Pacific studies, marine studies, agriculture, science and technology" (USP.ac.fj, 2013). Second is "The Fiji National University (FNU) was 'formally established in 2010'. FNU presently has campuses and centres at 33 locations throughout the country, with a staff complement of more than 1,800 and in January 2012, hitting a record student enrolment of more than 20, 000". The Fiji National University is "daily developing, innovating and expanding to provide Fiji and the region with the education and training that they most need" (FNU.ac.fj, 2017).

The third largest higher education institution is the University of Fiji in Saweni, Lautoka. The institution's objectives include "providing higher education relevant to Fiji's needs, but within a global framework and to support Fiji's development as a sustainable, peaceful, inclusive and progressive society committed to good governance" (UoF, n.d.). University of Fiji provides "Certificate, Diploma, Undergraduate Degree and Postgraduate levels in disciplines such as Accounting, Economics, Management, Computing Science, Information Technology, Mathematics and Language and Literature" (UoF, n. d.).

Government policy "has been very proactive and new institutions have been established, notably the Fiji Higher Education Commission (FHEC) and the Tertiary Scholarships and Loans Board (TSLB), to 'steer' the system, 
ensure regulatory oversight of quality and provide financial assistance to students” (Healey, 2018).

\section{Findings of Key Issues in Higher Education}

\subsection{The Culture of Plagiarism}

Plagiarism is a growing concern in higher education. Hart \& Friesner (2004) have labeled plagiarism as 'an endemic'; they state "prior to the mid-1990's examples of plagiarism appeared to be comparatively rare but the recent massification of higher education, noticeable as a world-wide phenomenon has raised concerns in the academic community that plagiarism may now be a serious and endemic problem". It can be defined as copying someone else's work without acknowledging the source which is supported by Culwin \& Lancaster (2001), "taking the words or ideas of another person and using them without proper acknowledgement is a commonly accepted definition of plagiarism". In their paper, Culwin \& Lancaster (2001), provide some insights into why students indulge in this unethical practice. It could be due to lack of time available before meeting the deadline as well as the misconception that any information available on the internet can be utilized freely.

Culwin \& Lancaster (2001) point out that "the perception of some students that material on the Internet is "free" and can be reused without citations and concludes that many institutions are ignoring the problem because they do not know how to cope with it". In a survey conducted by Dordoy (2002), some of the determinants responsible for learners engaging in plagiarism had been outlined as follows:

Table 1. Determinants for Plagiarism (Note 1)

\begin{tabular}{lll}
\hline & Students (\%) & Staff $(\%)$ \\
\hline Wanting to acquire a better score & 59 & 36 \\
Laziness or poor time management & 54 & 42 \\
Easy access to materials via the internet & 40 & 35 \\
Not considering the rules & 29 & 40 \\
It occurs unintentionally & 29 & 30 \\
\hline
\end{tabular}

In all courses he teaches, the researcher ensures that the topic of plagiarism is discussed in detail with the students so that they are aware of the consequences prior to submission of assignments. For instance, in the courses Basic Structure of the English Language and English for Academic Studies, the author firstly explains what plagiarism is. Therefore, in the first two weeks, he explains to them how to do in-text referencing as well as create bibliographies at the end of the written work. They practice these exercises in class. Then they move on with the write up of the research proposal (RP). To ensure that the researcher does not get the same RPs as the ones submitted by students from the previous semesters, he gets the students to come up with original topics which are recorded and if it is the same then they would need to provide another one.

This concept is also supported by Culwin \& Lancaster (2001), they claim "avoid issuing the same assignment requirements year after year, researching the subject area to check that model essays are not prevalent on the Internet and requiring drafts of submissions to minimize the opportunities for students to cheat". The researcher normally asks the leaners to choose 5 topics in consultation with him prior to approving a topic. Once, they have completed it, he has a look at their draft work and picks out the in-text references or places where referencing should have been done but they missed it out. They go back again and make the necessary changes.

Hart \& Friesner (2004, p. 93) also emphasize on the essence of teaching referencing skills, they advise that "citation skills need to be constantly taught, reinforced and stressed as an indication of worthy membership of the academic community. Both citation and referencing needs to be reinforced at critical intervals and not just in the first year".

In Fiji, the leading universities use plagiarism checking software such as Turnitin which is used at the 'Fiji National University' as well as "the University of the South Pacific". The soft copy of an assignment needs to be uploaded onto the 'drop box' which then runs a check for plagiarism throughout the document. It then shows the percentage of similarity index, the amount of information that was copied by the student without proper citations. A similar approach to combating plagiarism is highlighted by Culwin \& Lancaster (2001), who suggest the use of Findsame.com. This software "provides limited free detection for single submissions, via copy and paste into a text box, which can be useful to find Web plagiarism". However, Culwin \& Lancaster (2001) argue that "the best solution would simply see the culture of cheating eliminated; few people think this is possible, even if a combination of technical solutions placed alongside carefully designed courses and assignment specifications can reduce it to a minimum". 


\subsection{Influx in Enrolments and Workload}

In reviewing contemporary issues in 'Higher Education' in the South Pacific, it was found that the various issues that Thaman (2008) highlights are relevant to the author's teaching environment or the challenges that he faces. In particular, Thaman (2008) mentions 'over-crowded classrooms, heavy staff workload, deteriorating facilities, cramped office spaces and aging equipment are evidence of the need to control student enrolment'.

In Table 2, the enrolment figures for the three universities in Fiji are stated.

Table 2. Enrolments at the three major universities in Fiji (Note 2)

\begin{tabular}{cccccccc}
\hline & 2010 & 2011 & 2012 & 2013 & 2014 & 2015 & 2016 \\
\hline Fiji National University & 26,723 & 26,635 & 32,496 & 34,545 & 34,524 & 29,035 & 25,958 \\
University of the South Pacific & 20,056 & 21,594 & 23,667 & 24,986 & 25,825 & 26,658 & 27,642 \\
University of Fiji & 1,021 & 1,217 & 1,388 & 1,593 & 1,962 & 2,420 & 2,307 \\
Total & 47,800 & 49,446 & 57,551 & 61,124 & 62,311 & 58,113 & 55,907 \\
\hline
\end{tabular}

These issues are not only pertinent to 'the University of the South Pacific' but other tertiary institutions in Fiji. Tertiary institutions pay more emphasis on the number of students they are able to attract each enrolment drive and at the expense of this the quality is compromised. A similar perspective was highlighted in the Asian Development Bank (2011) report which stated "while enrolments soared, government budgets for higher education did not. For the most part, universities lacked the financial resources to maintain quality while expanding to absorb a larger and increasingly more diverse student body". The quality is placed at risk when the class size increases from 20 students to 50 in tutorials which does not allow sufficient time for learner participation or activities where students can practice IBL or PBL activities as time limits the way the lesson progresses. With a class of 50 students and only 2 hours' time allocated makes it challenging to ensure the quality is intact.

Further, Thaman (2008) highlights the point of workload which is a detrimental issue. If Academics are left to teach multiple courses and increase in workload each semester then when would they be able to spend time on research, writing and publishing which is the core aspect of being in academia. Again, this issue comes about when the MQR to enter the tertiary institutions in Fiji is not adhered to strictly or has been reduced to accommodate more enrolment numbers. Apart from these issues which relate to enrolment, issues such as cramped office space is largely due to the lack of infrastructural planning with an emphasis on inconsiderate thinking and underestimating the role of tertiary educators/academics. An academic needs enough space not only to store books but to engage in discussions with colleagues, collaborate with other universities in research or publishing and inviting someone in a cramped office can be beyond embarrassing.

Shin \& Harman (2009) discuss that as employers require "staff to enhance their job competencies, more than $10 \%$ of the students were over the age of 40 years" in universities. This is the same with some organizations in Fiji. Take for example, the Ministry of Education a few years ago announced that all teachers with a Diploma in primary and high schools needed to upgrade their qualifications to bachelor's in order to retain their jobs. Thereafter, there has been an influx in mature students opting for in-service courses to upgrade their qualifications.

Further, a crucial point that has been pointed out in both Thaman (2008) and Shin \& Harman (2009) is that with the substantial increase in class size "the role of college teachers/academics will be similar to that of high school teachers as they will only be teaching standardized curriculum" with less time allocated for their own research and professional development. It is in fact a growing concern for Fiji and a liability to quality education. There needs to be a balance in workload for those employed by higher education institutions so that they engage in on-going research with not only Fijian Academics but be able to successfully collaborate with international counterparts as well. It is suggested that Fijian universities should provide incentives as well as have specific staff responsible for allocating and bridging the connection between local researchers and international academics to promote quality education in tertiary institutions.

\subsection{Drawbacks in Enforcing Inclusive Education in HE}

In light of views expressed by Thaman (n.d) on inclusive education, she had focused on how culture needs to be integrated into the class. In particular, she focuses on the Pacific culture. Thaman gives an example of the framework that she developed kakala in order to encourage students to engage in doing research, Professor 
Unaisi Baba later developed the Vanua framework and in New Zealand the Kura Kaupapa Maori was developed.

In her discussions on inclusive education, Thaman, highlights the difficulties of encouraging individuals as well as institutions in working towards inclusive education. She also touches on gender issues. In particular, she gives example from New Zealand and Australia of not having any women Professor appointed to senior management posts such as VC, Pro VC or DVC. In fact, at the time she conducted that research (1990s) Thaman was the Pro VC Research and found it astonishing. One of the reasons she found in the research was the minimal number of senior management having women Professors, was that they felt they had to imitate their male counterparts and that they would not be taken seriously. In fact, in the author's tertiary institution or employer has more women in senior management posts than males; most of the Deans, Associate Deans as well as Pro VCs largely consist of women.

Further, Thaman (1991) identifies three more perennial issues which are pupil-related, curriculum related and teacher-related. On pupil related issues, she highlights about the students in Tonga who have difficulty in comprehending the lesson as it is delivered in English language which is either the second or third language for the students. To add on, Fiji had the 1969 Education Commission report which the government used after independence from the colonial rule. The report stated that for the first three years of primary school education, the students were to be taught i.e. the medium of instruction was to be in their mother tongue and from the fourth year it was to gradually change to the English language. However, this has not been followed closely and the curriculum set out by the MOE has not been able to deliver this in the class as students even in pre-school are being taught in the second language i.e. English and not in the mother tongue.

In 2000, there was the Fiji Education Commission report; Learning to Live Together which brought about the discussion on this issue. Again, it was not fully examined due to the 2000 coup but later governments have also not re-looked at this report to use the recommendations provided in it especially relating to the mother tongue, National language, language planning and policy as well as medium of instruction (MOI).

Further, Thaman (1991) concludes her paper with "an expounding statement that cultural analysis is an essential factor in making curriculum development more appropriate and meaningful in Pacific Island contexts. Moreover, it will assist curriculum planners in solving problems often related with materials production, trialing and implementation, especially problems associated to teachers' attitudes and behavior" (p. 10). In fact, the issue of the appropriateness of the curriculum being taught in the Pacific is not a new subject. ALIENATING (2001) states, "the concern with curriculum relevance in our region dates back to the early 1970s when the school curriculum was seen by Pacific Island leaders as an important instrument in preparing people for independence from various colonial masters".

In ALIENATING (2001, pp. 6-7), Thaman suggests six ways in maintaining inclusive education in the Pacific:

1. better 'contextualizing the curriculum';

2. developing "a new pedagogy based on Pacific values, beliefs and knowledge systems that incorporate Pacific styles of learning and ways of knowing";

3. reorienting "teacher education and training in order to ensure that all teachers are competent in, and have a deep understanding of, as many Pacific languages and cultures as possible";

4. developing "new forms of student assessment that take account if the anticipated changes in curriculum and pedagogy";

5. incorporating "indigenous Pacific processes, ways of management and administrative structures"; and

6. strengthening "research capabilities in the post-secondary institutions as well as in the various communities".

\section{Conclusion}

Fiji is the hub of the South Pacific where students from various countries in the Oceania turn to embark on their tertiary qualifications. This paper has highlighted key issues that are affecting the way higher education (HE) is progressing in Fiji. Plagiarism continues to be a growing concern for tertiary educators as students are able to access readily available literature that relates directly or indirectly to their assignments. The issue of increased enrolment which affects the workload of academic staff is tormenting. The paper brings to light the notion of inclusive education curriculum in HE with specific examples from Fiji and New Zealand. A collaborative effort from the three universities is crucial in order to combat these challenges. Further research involving individual tertiary intuitions on these subjects will draw substantial data on other pertinent issues in HE that continue to hinder the work of academics in attaining the highest standard of quality graduates. 


\section{References}

Alienating, S. A. C. (2001). Towards culturally inclusive teacher education with specific reference to Oceania. International Education Journal, 2(5).

Asian Development Bank (ADB). (2011). Higher education across Asia: An overview of issues and strategies. Asian Development Bank, Manila, Philippines.

Central Intelligence Agency. (2018). The world factbook: Fiji. Retrieved from: https://www.cia.gov/library/ publications/the-world-factbook/geos/fj.html

Dordoy, A. (2002). Cheating and Plagiarism: Staff and Student Perceptions at Northumbria. Northumbria Conference. Retrieved from http://online.northumbria.ac.uk/LTA/media/docs/Conference\%20Publicatio $\mathrm{n} \% 202002 / A D . d o c$

Culwin, F., \& Lancaster, T. (2001). Plagiarism issues for higher education. VINE, 31(2), 36-41, https://doi.org/10.1108/03055720010804005

FNU. (2017). University History. Retrieved November 22, 2017, from http://www.fnu.ac.fj/new/abtus/university-history

Glenn, M., \& D'Agostino, D. (2008). The future of higher education: How technology will shape learning. New Media Consortium.

Hart, M., \& Friesner, T. (2004). Plagiarism and poor academic practice-a threat to the extension of e-learning in higher education? Electronic Journal on E-learning, 2(1), 89-96.

Healey, N. (2018). International branch campuses, management of. In P. N. Teixeira, \& J. C. Shin (Eds.) Encyclopedia of international higher education systems and institutions. Springer.

Learning in the 21st Century: Teaching Today's Students on Their Terms (n. d). Retrieved October 24, 2017, from https://www.certiport.com/Portal/Common/DocumentLibrary/IEAB_Whitepaper040808.pdf

MA, H. K. C., \& Tandon, R. (2014). Knowledge, engagement and higher education in Asia and the Pacific.

Mangubhai, F., \& Mugler, F. (2003). The language situation in Fiji.

Shin, J. C., \& Harman, G. (2009). New challenges for higher education: Global and Asia-Pacific perspectives. Asia Pacific Education Review, 10(1), 1-13.

Thaman, K. H. (1991). Towards a culture-sensitive model of curriculum development for Pacific Island Countries.

Thaman, K. H. (2008). The role of higher education in regional development in Pacific Island countries with specific reference to the University of the South Pacific. UNESCO Forum on Higher Education, Research and Knowledge.

Thaman, K. H. (n. d). Role of Culture and Gender in Higher Education (video transcript).

UoF. (n.d). University Profile. Retrieved December 11, 2017, from https://www.unifiji.ac.fj/university-profile/

USP. (2013). USP Introduction. Retrieved November 22, 2017, from https://www.usp.ac.fj/index.php?id=usp_introduction

\section{Notes}

Note 1. Source: Dordoy (2002).

Note 2. Source: "Annual Reports to the Parliament of the Republic of Fiji”.

\section{Copyrights}

Copyright for this article is retained by the author(s), with first publication rights granted to the journal.

This is an open-access article distributed under the terms and conditions of the Creative Commons Attribution license (http://creativecommons.org/licenses/by/4.0/). 